\title{
Microsatellite Instability Analysis
}

National Cancer Institute

\section{Source}

National Cancer Institute. Microsatellite Instability Analysis. NCI Thesaurus. Code C63331.

A laboratory procedure to detect microsatellite instability. 